Provided for non-commercial research and education use. Not for reproduction, distribution or commercial use.

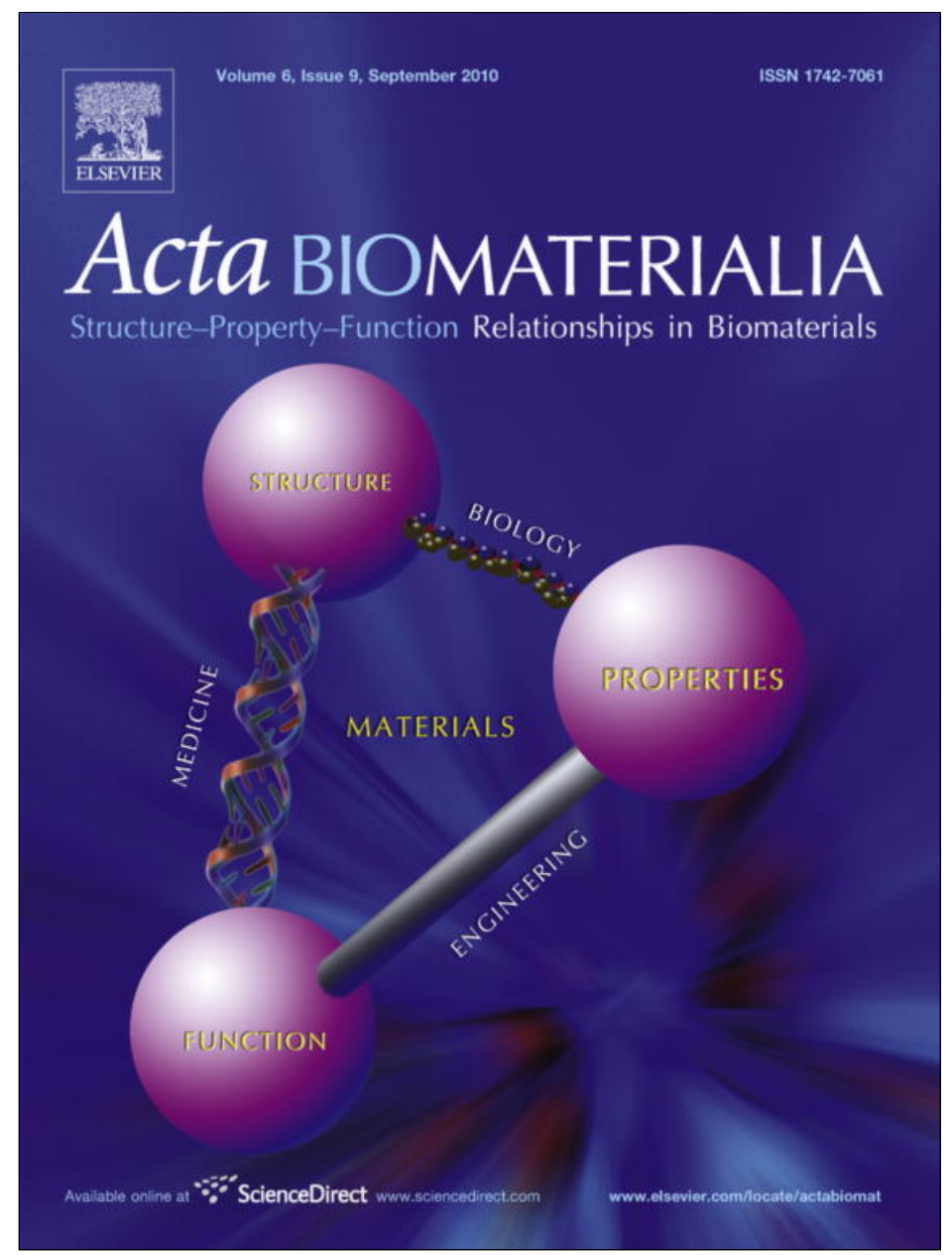

This article appeared in a journal published by Elsevier. The attached copy is furnished to the author for internal non-commercial research and education use, including for instruction at the authors institution and sharing with colleagues.

Other uses, including reproduction and distribution, or selling or licensing copies, or posting to personal, institutional or third party websites are prohibited.

In most cases authors are permitted to post their version of the article (e.g. in Word or Tex form) to their personal website or institutional repository. Authors requiring further information regarding Elsevier's archiving and manuscript policies are encouraged to visit:

http://www.elsevier.com/copyright 


\title{
Analysing protein competition on self-assembled mono-layers studied with quartz crystal microbalance
}

\author{
Johan Benesch, João F. Mano, Rui L. Reis * \\ 3B's Research Group (Biomaterials, Biodegradables and Biomimetics), School of Engineering, University of Minho, Avepark, 4806-909 Caldas das Taipas, Portugal \\ IBB (Institute for Biotechnology and Bioengineering), PT Government Associated Laboratory, Braga, Portugal
}

\section{A R T I C L E I N F O}

\section{Article history:}

Received 25 September 2009

Received in revised form 10 February 2010

Accepted 18 March 2010

Available online 21 March 2010

\section{Keywords:}

Competitive binding

Blocking

Interfacial relaxation

Sequential adsorption

Binary protein adsorption

\begin{abstract}
A B S T R A C T
The mechanisms by which proteins adsorb to surfaces of biomaterials have long been of interest. The present work started with the premise that small/hard and large/soft proteins will yield different sets of normalized frequency shift and dissipation signals when studied with a quartz crystal microbalance. The aim was to evaluate the usefulness of these raw data to study protein competition using protein incubations in sequence and from mixtures of albumin (BSA) and gamma-globulin (BGG) at various ratios. Increasing the concentration of BSA decreases the adsorption of subsequently incubated BGG. For BSA/ BGG mixtures the dissipation is similar for all logarithmic molar ratios BGG/BSA below 1 but soon decreases when the molar ratio of BSA/BGG (and opposite for the normalized frequency shift) is above 1 , indicating preferential binding of BGG. Modelling indicated that differences in the film shear modulus and viscosity depend more on the properties of the self-assembling mono-layers (SAMs) than on the proteins. Films high in BSA tentatively differ in film shear modulus and viscosity from that of films high in BGG but only on the hydrophobic surfaces. The results were encouraging as the raw data were deemed to be able to point at protein adsorption competition.
\end{abstract}

(c) 2010 Acta Materialia Inc. Published by Elsevier Ltd. All rights reserved.

\section{Introduction}

Key aspects of protein adsorption onto the surface of biomaterials are not only related to the adsorption kinetics and total amount but also to various aspects of competitive behaviour of blood proteins. The latter is probably more important when looking into the behaviour of complex protein solutions, especially with regard to activation of the humoral systems and exposure of cell receptor ligands. The present work is focused on competitive protein binding as a phenomenon on its own right. This is not a new field, going back to the pioneer works by researchers such as Vroman, whose early experiments with ellipsometry indicated that there are differences in which proteins can be detected with antibodies after different serum incubation times [1], and Brash, whose lab performed (as far as the authors know) the first experiment to show protein exchange [2,3], thus indicating that protein competition is important for biomaterials. They have been followed by many others using a large variety of techniques to study protein competition [4-18]. In the background to this work is also previous studies indicating that competitive protein binding can affect the interaction between cells (at least in vitro) with the sur-

\footnotetext{
* Corresponding author at: 3B's Research Group (Biomaterials, Biodegradables and Biomimetics), School of Engineering, University of Minho, Avepark, 4806-909 Caldas das Taipas, Portugal. Tel.: +351 253604498

E-mail address: rgreis@dep.uminho.pt (R.L. Reis).
}

faces of biomaterials [19-21], again highlighting the interest in competitive protein adsorption in relation to biomaterials.

The starting point for this work is the premise that proteins with different size and overall characteristics (e.g. small/hard and large/soft) will yield a different response pair (frequency shift and dissipation) in a quartz crystal microbalance with dissipation (QCM-D), when incubated at similar concentrations (Fig. 1). Such a response most likely will also depend on the surface properties of the biomaterial. QCM-D is a unique technique that relies on two aspects of adsorbed films: (i) the adsorbed mass is a function of the changes in resonance frequency of the measurement crystals upon protein adsorption, and (ii) the decay of the resonance amplitude is related to viscosity of the film. One of the main drawbacks is that the obtained signal also is sensitive to the mass of the water captured in films and the viscosity of solutions, which makes the subsequent necessary modelling the largest hurdle in analysing the results.

The focal point of this work is thus to evaluate to what extent the analysis of the raw data from QCM-D will indicate about protein competition in sequence and mixtures, using albumin and gamma-globulin as the model system since there is a marked difference in their size and mass. Also, the competitive behaviour of adsorption of albumin and gamma-globulin or IgG has been studied by other techniques $[5,7,8]$ which is important when discussing the approach. 


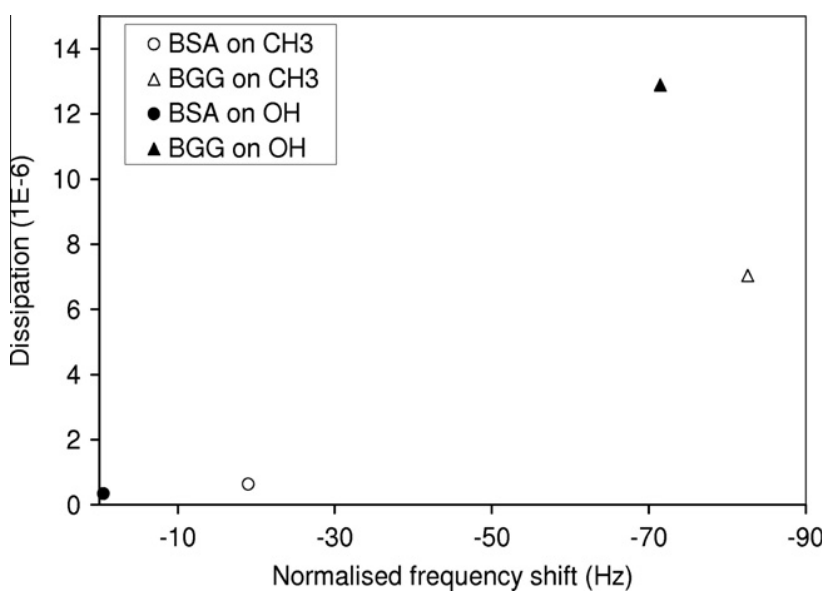

Fig. 1. Dissipation vs. frequency shift of BSA and BGG adsorbed alone at $\mathrm{OH}$ - and $\mathrm{CH}_{3}$-terminated SAMs for $15 \mathrm{~min}$ followed by $15 \mathrm{~min}$ rinse in $50 \mathrm{mM}$ Tris $145 \mathrm{mM}$ $\mathrm{NaCl} \mathrm{pH} \mathrm{7.4.}$

\section{Materials and methods}

Bovine serum albumin (BSA, pI 5, $M_{\mathrm{W}} 66 \mathrm{kDa}$, Sigma) and bovine gamma-globulin (BGG, pI 6.5-9.5, $M_{\mathrm{W}} 150-900 \mathrm{kDa}$, Sigma) were dissolved in $50 \mathrm{mM}$ Tris (Merck), $145 \mathrm{mM} \mathrm{NaCl}, 0.05 \% \mathrm{NaN}_{3}$ at $\mathrm{pH} 7.4$ at room temperature (RT). Solutions were stored at $8^{\circ} \mathrm{C}$ for less than a week. These proteins were incubated for 1530 min at $25^{\circ} \mathrm{C}$ at total $1 \mathrm{mg} \mathrm{ml}^{-1}$ in a quartz crystal microbalance (E4, Qsense) onto gold coated crystals (Tangidyne and Qsense) that were previously coated with alkane thiols. The gold surfaces were cleaned by sonication for 3 min each in acetone and ethanol followed by $1 \mathrm{~h}$ UVO/ozone (Pro, Bioforce nanosciences) on each side, then more $3 \mathrm{~min}$ sonication in ethanol to remove loose organic remnants. The cleaned crystals were incubated in $20 \mu \mathrm{M}$ ethanol solution of C16-SH (Fluka) or HS-C11-OH (Sigma) for at least two nights to ensure well formed mono-layers [22]. The alkane thiol coatings were analysed with contact angle goniometry (OCA15+, Dataphysics) using the circle fit algorithm with sessile drop of water $(2 \mu$ l, HPLC quality). The crystals were dried with flowing nitrogen prior to UVO treatment and measurements. The QCM responses in frequency and dissipation were used to study the feasibility of multilayer formation and potential preferential binding for BSA and BGG. The pumping speed was set at $50 \mu \mathrm{min}^{-1}$, giving laminar flow as indicated by the manufacturer. The crystals were run in buffer (Tris) for at least $15 \mathrm{~min}$ to assure a stable baseline. Except for the repeats of BSA and BGG the data points were only taken from Tris rinsing after the protein incubations to rule out influence of the protein solution itself on the QCM responses, although $1 \mathrm{mg} \mathrm{ml}^{-1}$ solutions of these proteins usually only impose small changes (apart from the adsorbed proteins). The frequency and dissipation values at the end of each experiment were used as the basis for most of the analysis. The full experimental runs were in some cases modelled using the QTools software (QSense) with the Voigt model which uses the assumption that the viscoelastic properties of a material can be described by a parallel spring and viscous damper. In some of the graphs the logarithm of the molar ratio of BSA and $\mathrm{BGG}$ is used, $\log (\mathrm{mol}(\mathrm{BSA} / \mathrm{BGG}))$, under the assumption that $\mathrm{BGG}$ is only IgG. Since it is difficult to find good experimental fits by using a as wide as possible range for the fitting parameters, initially a smaller range was chosen based on published result $[6,23]$ as follows: fundamental tone $5 \mathrm{MHz}$, fluid viscosity $1 \mathrm{mPas}$, fluid density $1000 \mathrm{~kg} \mathrm{~m}^{-3}$, film density $1150 \mathrm{~kg} \mathrm{~m}^{-3}$, layer viscosity $0.001-$ $0.1 \mathrm{mPas}$, layer shear modulus $100-2000 \mathrm{kPa}$ and layer thickness $0.01-100 \mathrm{~nm}$. Choosing to fix the fluid viscosity and density to that of water [6] was deemed reasonable for two reasons: firstly, only low protein concentrations were used which was also noted in the very low change of dissipation going from incubation to rinse; secondly, the current study was more concerned with the values after rinse, not of those during the actual incubation. Notably the density of the protein film can actually depend on the molecular mass of the studied proteins [24]. In modelling density and thickness are reciprocal, implying that variations in either will to a large extent cancel each other when calculating surface mass density. Since this study used protein mixtures it was deemed more practical to assume a fixed value for the protein film density. Statistical evaluation of the triplicate or more experiments (except Fig. 1) was done with Student's $t$-test, only reporting differences if they were found to be equal or better than $5 \%$ confidence level. The values in the graphs are mean \pm standard error of mean.

\section{Results and discussion}

The water contact angles were found to be $113^{\circ}(6)$ for $\mathrm{CH}_{3}-$ SAMs and $17^{\circ}(6)$ for OH-SAMs, thus with distinctly and statistically different levels of surface energy. In this section, the obtained QCM data will be discussed in the light of some published approaches to assess the QCM raw data vs. QCM modelling using the Voigt model and published results on protein competition and adsorption, with QCM and other methods.

In sequential incubation of proteins, albumin (BSA) seems to adsorb at a very limited extent on BSA from previous incubations under the used experimental setup (Fig. 2). In contrast, gamma-
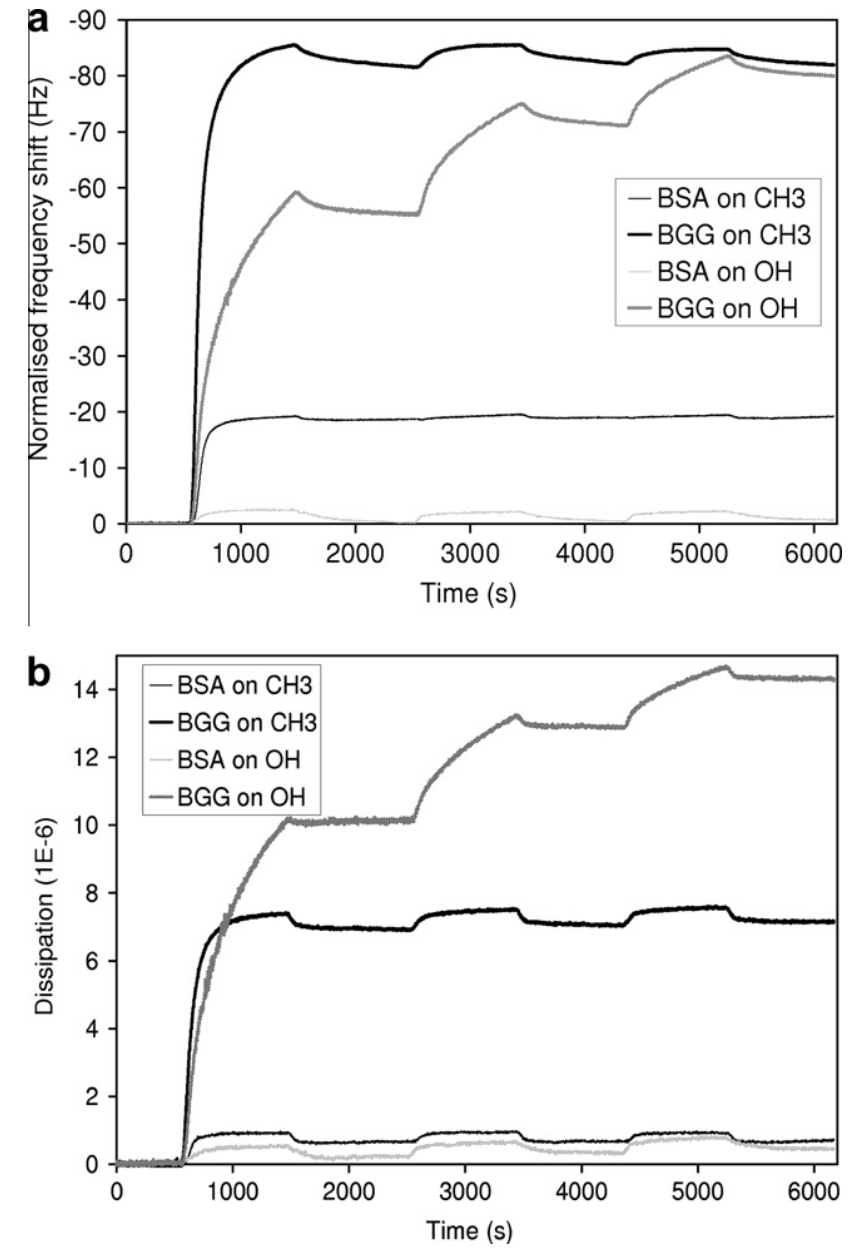

Fig. 2. (a) Normalized frequency shift of third overtone of 3 repeated incubations of $1 \mathrm{mg} \mathrm{ml}^{-1}$ BSA and BGG incubated on $\mathrm{OH}$ and $\mathrm{CH}_{3}$-terminated SAMs followed by rinse in Tris. (b) Dissipation of same experiments as in (a). 
globulin (BGG) does adsorb on layers formed by previous incubations of BGG on OH-SAMs but not to any discernible extent on $\mathrm{CH}_{3}$-SAMs. This could be partially explained by still available asorption sites for BGG after the first incubation on OH-SAMs. It should be noted that gamma-globulins contain $\operatorname{IgG}$ (pI 6.5-9.5), IgA (pI 4.5-6.5) and IgM (pI 4.5-6.5) [25], although the mass concentration of IgG is roughly 5-6 higher than for each IgM and IgA [26]. One might have expected there to be an influence of this large range of pIs that overlap with the buffer $\mathrm{pH}$, but then uncertain why this is only seen one type of surface. In the case of OH-SAMs when BGG is incubated on itself the frequency and dissipation shifts decrease by the number of incubations, indicating that the surfaces is getting closer to saturation. The differences in the behaviour for could be explained by the different surface energies, i.e. favouring adsorption on the hydrophobic $\mathrm{CH}_{3}$-SAMs. Although BSA has similarly very low dissipation for both surfaces, it is much higher for BGG and then higher on the OH-SAMs, Fig. 2b. This implies that the BGG films are more viscoelastic than BSA. This could also mean that BGG films have changed their conformation more on $\mathrm{CH}_{3}$ than OH-SAMs. Although BSA is not resistant to conformational changes upon adsorption [27], it seems that the conformation changes and relaxation decrease with increasing surface coverage [28] which could be due to proteins arriving at low coverage surface having more time and space to rearrange or unfold $[29,30]$, although the rate to spread also depends on the surface [14]. Hence a shorter time to plateau in the amount of adsorbed proteins might indicate faster changes in conformation (with less surface diffusion) hence shorter time until the surface packing limit is reach. As noted in previous studies for some proteins there is a shift in the final adsorbed amount in short term (less than a few hours) when their concentration is around $0.01-0.1 \mathrm{mg} \mathrm{ml}^{-1}$. BSA concentrations above that lead to a plateau (saturation level) in the adsorbed amounts whereas for IgG it does not level off so quickly [31,32] up to ca. $10 \mathrm{mg} \mathrm{m}^{-1}$ (still far below physiological levels). This result could be explained by the fact that the competitive adsorption from protein mixtures also is influenced by the concentration at which the protein reaches this shift. Thus, differences in this level might influence protein competitiveness and partially explain the dependence of this competitiveness on the pair of proteins under study. Similar arguments have already been put forward with emphasis on the differences between proteins in the rate of their interfacial relaxation [14], which in turn could influence the above-mentioned concentration related shift and the height of the plateau in surface mass density.

Pre-incubation with an increasing concentration of BSA seems to have increased capacity to block further protein adsorption (see Fig. 3), being more effective on hydrophobic surfaces. Notably even at fairly low concentration $\left(0.01 \mathrm{mg} \mathrm{ml}^{-1}\right)$, BSA is capable of hindering BGG from adsorbing on both surfaces, although on $\mathrm{OH}-$ SAM this is not dramatically different from that of hundred times higher concentration, $1 \mathrm{mg} \mathrm{ml}^{-1} \mathrm{BSA}$, see Fig. 3c. As seen in Fig. 3c, increasing BSA concentration over the whole studied range continued to increase the blocking capacity on $\mathrm{CH}_{3}$-SAMs. This is consistent with previously noted results that sequential adsorption (first albumin then fibrinogen or immunoglobulin) can decrease the adsorption of the proteins in the second incubation step [5,11-14]. Previous studies with IgG and BSA also point out the results dependence on pre-incubated protein and the surface tension of the initial surface [12], although one should not rule out that some level of conformation changes in the protein films can explain part of the QCM results in this study.

In the present study the pre-incubation has a much bigger effect on the frequency shift than on the dissipation on OH-SAMs. The greater efficiency of BSA to block BGG on $\mathrm{CH}_{3}-\mathrm{SAM}$ than OH-SAMs could be explained as a consequence of greater conformational changes of BSA on a hydrophobic surface, thus making it more dif-
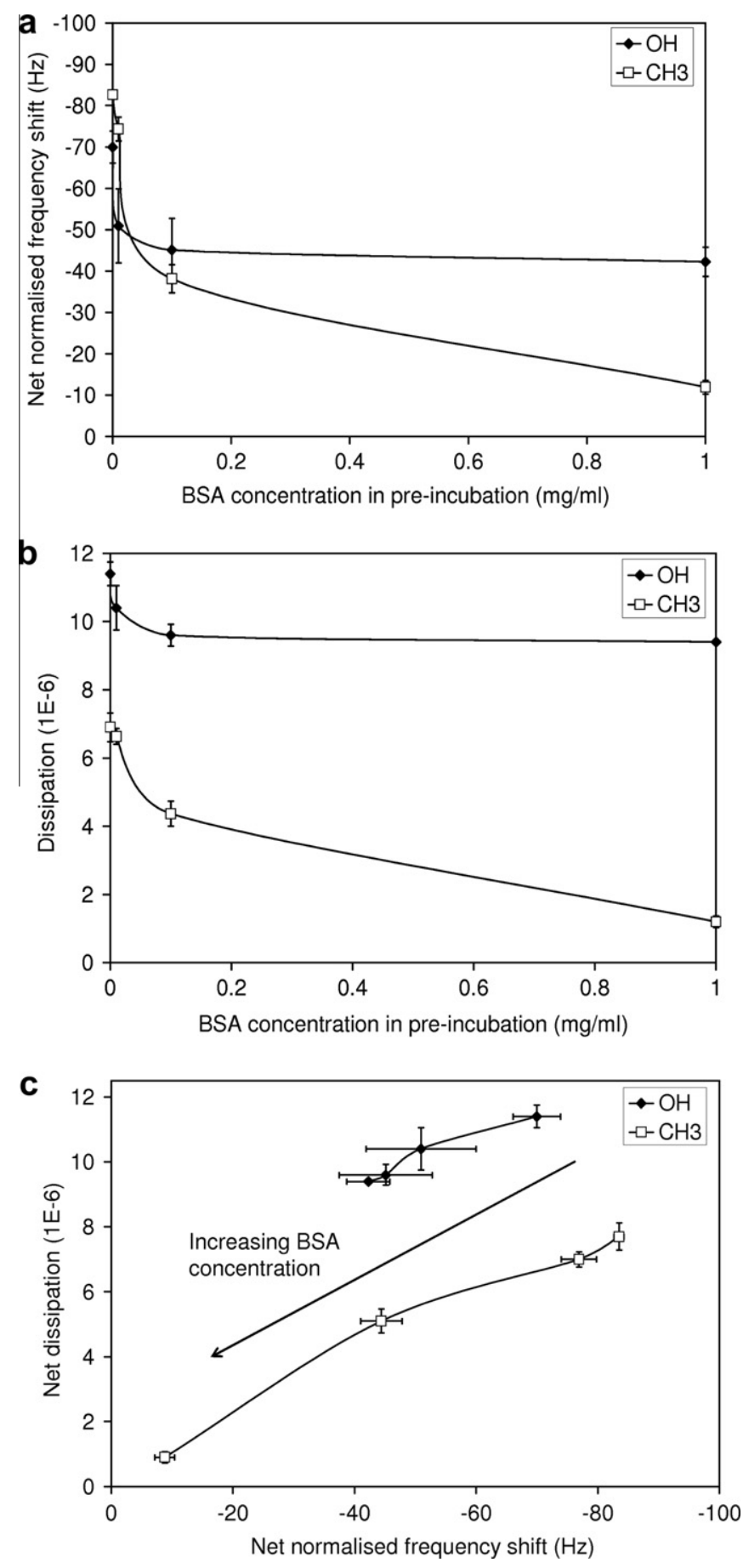

Fig. 3. (a) Frequency shift of $1 \mathrm{mg} \mathrm{ml}^{-1}$ BGG adsorption after pre-incubation with BSA at various concentrations $\left(0-1 \mathrm{mg} \mathrm{ml}^{-1}\right)$ on $\mathrm{OH}$ and $\mathrm{CH}_{3}$-terminated SAMs. Fifteen minutes incubation and rinse in all steps. (b) Dissipation values from the same experiments as in (a). (c) Plot of dissipation vs. normalized frequency shift of the values in (a) and (b). The concentration of BSA in the pre-incubation increases as the curves approach the origin.

ficult for subsequently arriving proteins to displace the earlier arrivals.

It has been noted that BSA reaches a plateau in adsorbed amounts, the level of which depends on the surface energy [31]. Generally one could perhaps view this in terms of surface affinity [7] that could be due to the formation of hydrophobic pockets on BSA, which in turn can induce more such pockets [33]. Depending on the time and concentration of the first incubation these proteins 
may reach various levels of saturation. The level depends on the time scale of incubation and rinse that could also give time for proteins to relax [17,28,34], making even low concentrations reasonably efficient in blocking subsequently arriving proteins. The blocking efficiency would then also depend on how the surface properties affect protein-surface interactions [28]. For example BSA on the air-water interface (air is hydrophobic by definition) unfolds to a greater degree at lower surface coverage [35]. All these findings would seem to be consistent with the finding of higher blocking capacity at $\mathrm{CH}_{3}$-SAMs in this study.

For the studied concentration range and time scale it seems that in terms of frequency shift and dissipation BGG at OH-SAMs is more sensitive to small changes in BSA concentration, but on $\mathrm{CH}_{3}$-SAMs it is easier to reach more complete blocking of BGG. This would also seem to fit with earlier findings suggesting that BGG is easily displaced by other proteins on a hydrophilic surface since they are more easily detached on such surfaces [5]. Also, because BGGs are prone to change their conformation which in turn might increase their affinity for the surface, making them more difficult to displace [7]. This difference in blocking capacity also fits with earlier findings that BSA can attain their native structure after resorption from hydrophilic surfaces but not from hydrophobic ones [29].

Concomitant adsorption from binary protein mixtures was also tested. When equal molar binary solution was used for incubation, the response was very near to that of BGG, indicating that they are more competitive than BSA on both surfaces (Fig. 4). When the mixture is richer in BGG there is not much change in both frequency shift (Fig. 4a) and dissipation (Fig. 4b) over the studied range. Most of the change (going from BGG to BSA solution) in both frequency shift and dissipation takes place for the solutions with higher concentration of BSA. Thus it would seem to be a preferential binding of BGG over BSA on these surfaces.

Notably, overall the frequency shifts were very similar on both surfaces for all molar ratios (no statistically significant differences were found except for logarithm of molar ratios 1.5 and 2). Differences were noted for the dissipation response (Figs. 1 and $4 \mathrm{~b}$ ) between the surfaces (statistically significant at 5\% level for all but $\log$ molar ratios 0,2 and 3), indicating a lower dissipation on the more hydrophobic surfaces, except for the highest BSA/BGG ratio and pure BSA for which the dissipation values for each surface were fairly close. One should note that not only molar ratios but also absolute concentration, dilutions and time of the experiment may influence the competitive behaviour of the chosen protein system $[15,16]$.

Plotting dissipation vs. frequency shift can be used to study the difference in adsorption behaviour between surfaces or biopolymers, especially when the dissipation is not negligible. Such a plot was used for the final values for all molar ratios (Fig. 4c), indicating that the protein films are more viscoelastic on the hydrophilic surfaces. This current approach to study competitive behaviour of mixtures is of course limited only to proteins that have relatively marked difference in frequency shift and/or dissipation.

Other studies have reported an increase in the total amount of adsorbed proteins for some protein pairs compared with singleprotein experiments $[11,12]$. It was suggested that albumin can facilitate the adsorption of the other protein. No such tendency was noted for either frequency shift, dissipation or modelled protein film thickness in the current study. One study that measured surface tension after protein adsorption indicated that in mixtures of BSA and IgM these two adsorb reversibly with only negligible irreversible adsorption on hydrophobic surfaces, which seems to contradict the findings of both the mixtures and sequential binding in this study [36]. Another way of expressing this is that they are equally good at competing for the surface, although it should be noted that IgM is only a minor fraction of BGG.
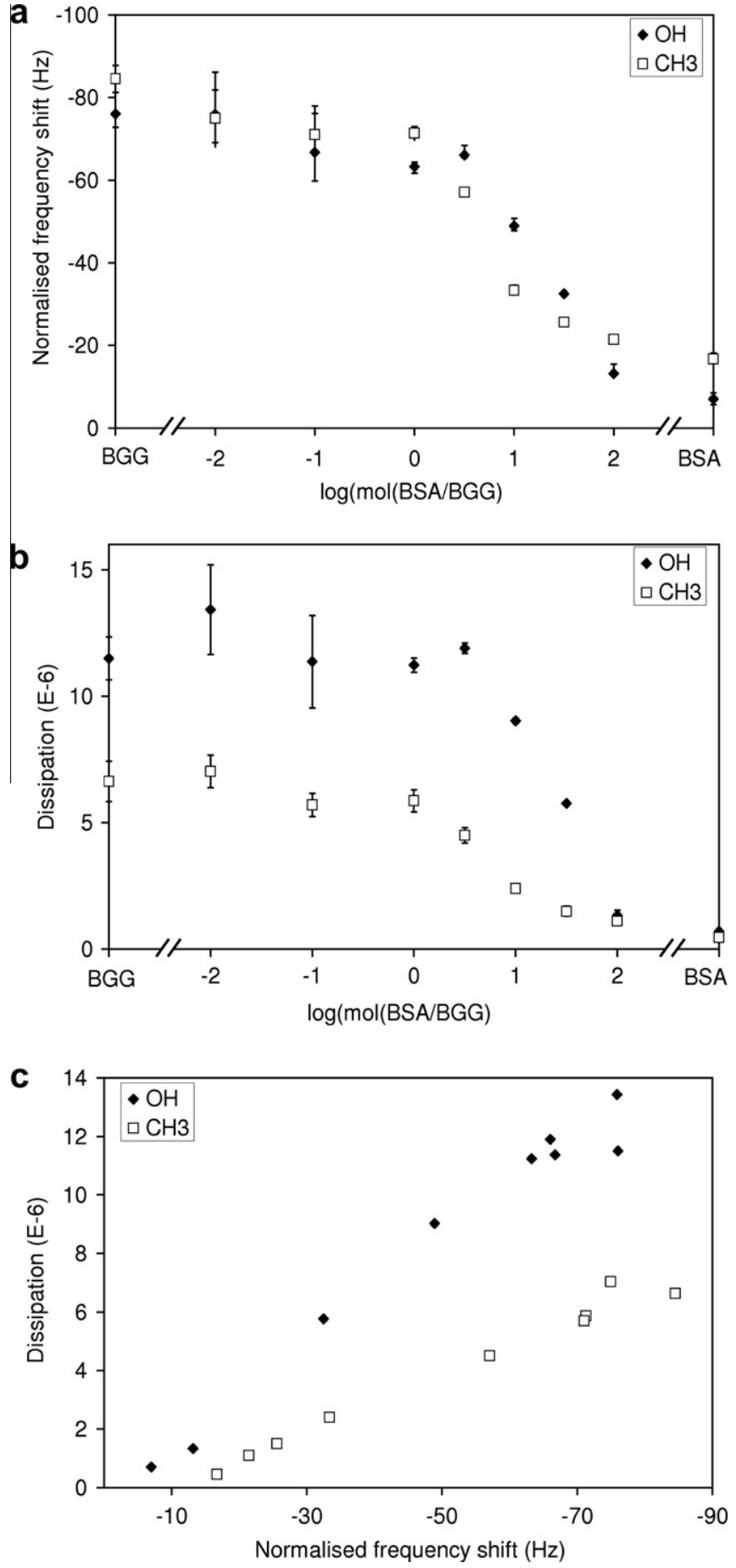

Fig. 4. (a) Normalized frequency shift (third overtone) vs. molar ratio for BSA/BGG mixtures (total protein concentration $1 \mathrm{mg} \mathrm{ml}^{-1}$ ) incubated and rinsed for $30 \mathrm{~min}$ on $\mathrm{OH}$ - and $\mathrm{CH}_{3}$-terminated SAMs. (b) Dissipation vs. molar ratio from same experiments as in (a). Error bars are standard error of mean $(N=3-4)$. (c) Plot of dissipation version normalized frequency shift of data in (a) and (b).

For the modelled data there is very good correlation between normalized frequency shift (third overtone) and modelled thickness for protein films on $\mathrm{CH}_{3}$-SAMs $\left(R^{2}=0.99\right)$, although the linear correlation starts to break up at shifts larger than $50 \mathrm{~Hz}$ for OHSAMs $\left(R^{2}=0.91\right)$ (Fig. 5a). Assuming a linear relationship the correlation coefficient is 0.94 for $\mathrm{CH}_{3}$-SAMs and 0.44 for OH-SAMs for normalized frequency shifts above $50 \mathrm{~Hz}$, indicating a drastic loss of correlation at $\mathrm{OH}-\mathrm{SAM}$ for these larger frequency shifts. These 

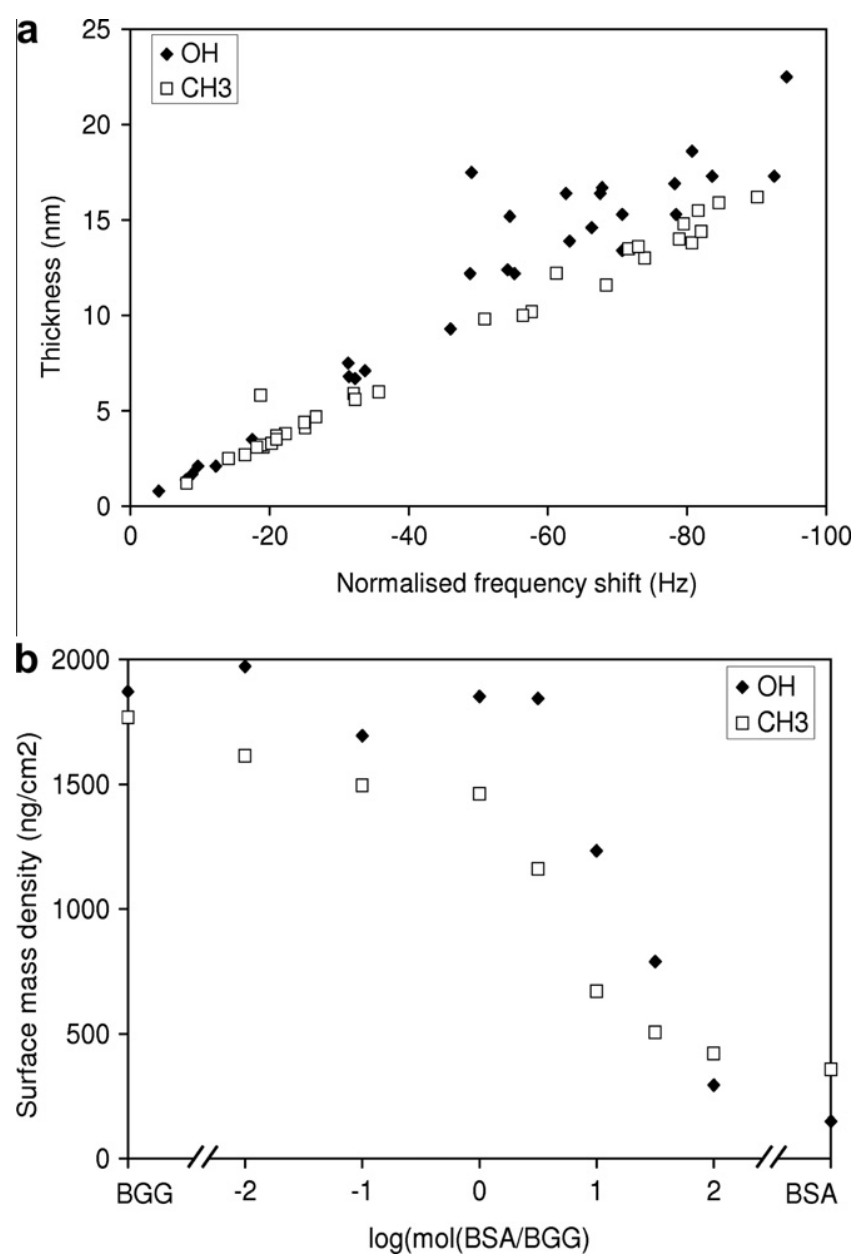

Fig. 5. (a) Modelled thickness vs. normalized frequency shift based on data from the experiments in Fig. 4. (b) Modelled surface mass density vs. molar ratio based on data from the experiments in Fig. 4.

larger frequency shifts are noted in layers that probably dominantly contain BGG thus possibly also contain more water but that would not in itself explain the increase in scatter.

A previous study argued that mono-layers of BSA or IgG would reach $200 / 500 \mathrm{ng} \mathrm{cm}^{-2}$, respectively, 500/1500, depending on whether they are laying down or standing on-end [11]. In this study, for BSA the modelling points were $150(1.3 \mathrm{~nm})$ and 360 (3.1 $\mathrm{nm}) \mathrm{ng} \mathrm{cm}^{-2}$ on $\mathrm{H}$-SAMs and $\mathrm{CH}_{3}$-SAMs, respectively; the same values for BGG were 1870 (16.3) and $1770(15.4 \mathrm{~nm})$ $\mathrm{ng} \mathrm{cm}{ }^{-2}$, respectively (Fig. 5b). Perhaps not surprisingly the BSA seems to have adsorbed at various orientations. For BGG it is not so easy to draw conclusions since IgM is so much larger than IgG, but since the majority of BGGs are IgGs it would seem that only a small fraction is laying down.

Notably the modelled surface mass density was found to be higher on OH-SAMs for all log molar ratios except 2 and only BSA (Fig. 5b), although this is also expected to be due in part to water trapped in the protein films, especially since QCM-D is sensitive to the effective mass of the adsorbed films [24]. Some reported literature values for non-QCM detection of single protein films are IgG $250-700 \mathrm{ng} \mathrm{cm}^{-2}[32,37,38]$ on $\mathrm{CH}_{3}$ terminated surface and $50 \mathrm{ng} \mathrm{cm}^{-2}$ on $\mathrm{OH}$ terminated surface [38]; and BSA films on $\mathrm{CH}_{3} 100-200 \mathrm{ng} \mathrm{cm}^{-2}[38,39]$ and $10 \mathrm{ng} \mathrm{cm}^{-2}$ on $\mathrm{OH}$ [38]. This would indicate water content in the range of 50-95\% in these layers. This is in stark contrast with another study that indicated that mass density values from QCM-D of IgG films on hydrophobic surfaces are overestimated by a factor of 1.5 with only $10 \%$ water, although based on the assumption of protein density of $1.4 \mathrm{~g} \mathrm{~cm}^{-3}$ compared to 1.15 that was used in the current study [32]. A modified Sauerbrey equation has been developed to take into account the viscoelastic properties of the adsorbed films [23,40], although it relies on a different QCM measurement approach to the one in the current study.

For single-protein experiments it has been indicated that the water content of protein films is linear with the dissipation value (at least up to $5 \times 10^{-6}$ ) but not necessarily proportional [24], for BSA around $250 \mathrm{ng} \mathrm{cm}^{-1} / 10^{-6}$ and IgG up to a factor 5 higher. Using these relationships to interpolate and extrapolate the data in the current study indicates more water than the estimated surface density of proteins, but then the surfaces were not the same [24]. Clearly it is not straightforward to compare the results with other studies, partially due to the differences in the surface chemistries and protein incubation protocol. Also, there is increasing evidence that some proteins such as IgG and other non-globular proteins might spontaneously form multilayers or surface aggregates $[5,11,36]$.

It has been suggested that the mechanical properties of the adsorbed proteins may affect their competitive behaviour $[6,18]$ with "soft" proteins being more competitive since they can easily rearrange or unfold to occupy more surface per molecule, which in turn could impede them being displaced by subsequently arriving proteins. The plots of modelled viscosity and shear modulus of the adsorbed films indicate that overall both these values are higher for protein films formed on $\mathrm{CH}_{3}$-SAMs than on OH-SAMs (Fig. 6). The difference is statistically significant at $5 \%$ level for the modelled viscosity values for all mixtures but not for shear modulus. This could be interpreted as proteins changing their conformation to more compact forms on $\mathrm{CH}_{3}$-SAM than on the $\mathrm{OH}$-SAMs. The viscosity at OH-SAMs seems to be $2 \mathrm{mPas}$ for all mixtures, whereas for $\mathrm{CH}_{3}$ SAMs it starts at 3 . When $\log$ molar (BSA/BGG) ratio is 1 it starts to increase, reaching $4 \mathrm{mPas}$ for BSA, although this change is not statistically significant. The trend is not so clear for the shear modulus but seems to be fairly stable around $200 \mathrm{kPa} \mathrm{OH}-\mathrm{SAMs}$ and almost double just for BSA. For $\mathrm{CH}_{3}$-SAMs the values vary between ca. 300 and $500 \mathrm{kPa}$ but are in most cases not significantly different from each other, whereas for BSA it reaches ca. $1200 \mathrm{kPa}$ (but with large standard deviation). For OH-SAMs there is no significant difference between BGG and BSA for both shear modulus and viscosity. Currently the authors have no obvious explanation why there is such a large significant (at $5 \%$ level) shift in film shear modulus between pure BSA and the other solutions at $\mathrm{CH}_{3}$-SAMs.

From plotting viscosity vs. shear modulus for the BSA/BGG mixtures (Fig. $6 \mathrm{c}$ ) it is clear that the values for $\mathrm{OH}$ - and $\mathrm{CH}_{3}$-SAM form two different clusters, albeit within each there is no clear correlation between the two film properties. Only when looking at the two groups together can one hint at a tendency for a positive correlation between them.

Other researchers have suggested assessing the stiffness of the films using the ratio normalized frequency shift and dissipation shift $(|\Delta F / n| /|\Delta D|)$ or its inverse [41,42], although the rationale and physical interpretation of this ratio are not very clear in these studies. Overall this value gives the same indication as the modelling of the behaviour of mixtures near $6 \mathrm{MHz}$ on OH-SAM rising to 10 for the two highest $\mathrm{BSA}$ ratios, on $\mathrm{CH}_{3}$-SAMs near 13 rising at $\log (\mathrm{BSA} / \mathrm{BGG})=1.5$ to 17 up to 36 for BSA only. Similarly the BGG layer in the sequential adsorption is around 6 at OH-SAM and 10 at $\mathrm{CH}_{3}$-SAM, indicating a slight difference between the two surfaces. Overall there seems to be little correlation between this ratio and modelled stiffness. On the other hand an interesting level of correlation was noted between this ratio and the modelled film shear modulus, see Supplemental information.

Despite interesting results, it does not seem feasible that QCMD could be used to directly study exchange mechanisms. Typically, this would require an unequivocal signal (such as obtained via 

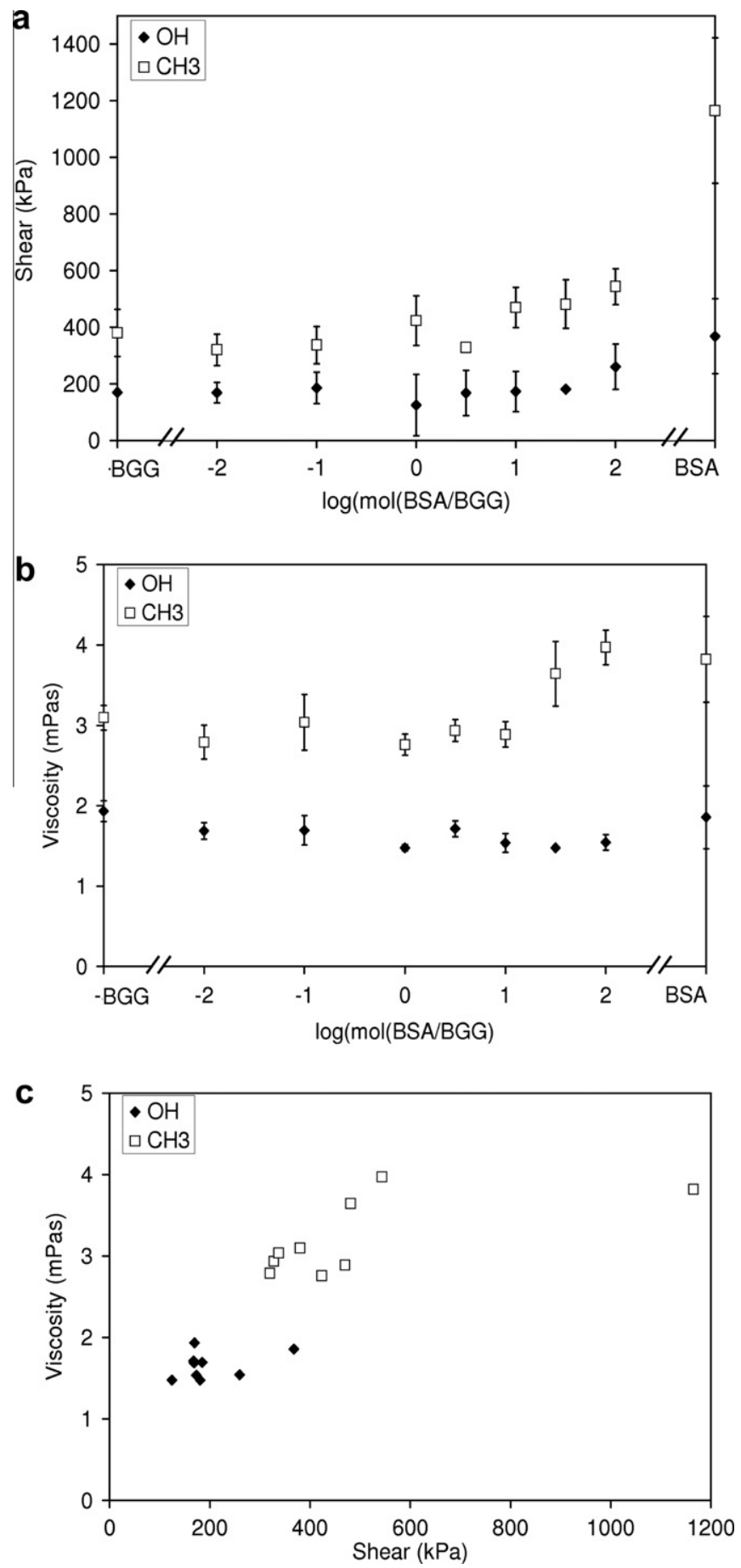

Fig. 6. (a) Modelled film shear modulus vs. molar ratio, based on data from same experiments as in Fig. 4. (b) Modelled film viscosity vs. molar ratio, based on data from same experiments as in Fig. 4. (c) Plot of modelled viscosity vs. modelled shear modulus of data in (a) and (b).

radio-labelling) from the proteins that are expected to exhibit such behaviour $[2,5,15]$. If the approach is combined with detection by antibodies such as in the initial works by Vroman, at least the antigenic expression of the studied proteins could be studied. Optical methods have successfully used the Vroman approach to study the adsorption of the BSA and IgG $[12,16]$ depending on concentration, ratios and sequential incubation. Also, future research should include independent means to quantify the protein films in order to be able to evaluate the impact of water content on the measured and modelled parameters.

\section{Conclusions}

QCM-D was used to study the adsorption of BSA and BGG on $\mathrm{OH}-$ and $\mathrm{CH}_{3}$-terminated SAMs. Under the studied experimental conditions, BGG can adsorb to surfaces pre-incubated with BGG itself on OH-SAMs, although this was not observed for the other combinations of protein and surfaces. Sequential protein adsorption starting with BSA indicates that its blocking efficiency toward the subsequent binding of BGG (by adsorption on available sites or by displacing BSA) is higher on hydrophobic surfaces and at higher concentration. Overall blocking of BGG was sensitive to even low concentrations of BSA $\left(0.01 \mathrm{mg} \mathrm{ml}^{-1}\right)$ but only for $\mathrm{CH}_{3}-\mathrm{SAM}$ was it possible to reach near total blocking in the studied BSA concentration range. Protein adsorption from BSA:BGG mixtures with molar ratios from 100:1 to $1: 100$ seems to indicate that $B G G$ is more competitive on both surfaces, being more efficient on the hydrophilic surfaces, as seen by the modelled total thickness of the formed protein films. It was not possible to assess the influence of water binding by the current approach. Hence, the analysis is not unequivocal. For all mixtures the protein films were thinner on OH-SAMs, and more rigid on $\mathrm{CH}_{3}$-SAMs. The modelling did not yield any significant difference in viscosity between BSA and BGG for both surfaces.

\section{Acknowledgements}

The authors thank the Portuguese National Science and Technology Foundation (FCT) for the Project Grants PTDC/FIS/68517/ 2006 and PTDC/FIS/68209/2006, and personal Grant BPD/39331/ 2007 for J.B.

\section{Appendix A. Supplementary data}

Supplementary data associated with this article can be found, in the online version, at doi:10.1016/j.actbio.2010.03.027.

\section{References}

[1] Vroman L, Adams AL. Findings with recording ellipsometer suggesting rapid exchange of specific plasma proteins at liquid/solid interfaces. Surf Sci 1969;16:438-46.

[2] Brash JL, ten Hove P. Transient adsorption of fibrinogen on foreign surfaces: similar behavior in plasma and whole blood. J Biomed Mater Res 1989;23(2):157-69.

[3] Brash JL, Scott CF, ten Hove P, Wojciechowski P, Colman RW. Mechanism of transient adsorption of fibrinogen from plasma to solid surfaces: role of the contact and fibrinolytic systems. Blood 1988;71(4):932-9.

[4] Holmberg M, Stibius K, Larsen N, Hou X. Competitive protein adsorption to polymer surfaces from human serum. J Mater Sci Mater Med 2008;19(5): 2179-85.

[5] Holmberg M, Hou X. Competitive protein adsorption: multilayer adsorption and surface induced protein aggregation. Langmuir 2009;25(4):2081-9.

[6] Welle A. Competitive plasma protein adsorption on modified polymer surfaces monitored by quartz crystal microbalance technique. J Biomater Sci Polym Ed 2004;15(3):357-70.

[7] Tremsina YS, Sevastianov VI, Petrash S, Dando W, Foster MD. Competitive adsorption of human serum albumin and gamma-globulin from a binary protein mixture onto hexadecyltrichlorosilane coated glass. J Biomater Sci Polym Ed 1998;9(2):151-61.

[8] Tremsina YS, Sevastianov VI. Competitive adsorption of human albumin and globulin onto polydimethylsiloxane from a model solution. Biomater Living Syst Interact 1995;3(3-4):103-10.

[9] Michiardi A, Aparicio C, Ratner BD, Planell JA, Gil J. The influence of surface energy on competitive protein adsorption on oxidized NiTi surfaces. Biomaterials 2007;28(4):586-94.

[10] Teske CA, von Lieres E, Schröder E, Ladiwala M, Cramer A, Hubbuch SM, et al. Competitive adsorption of labeled and native protein in confocal laser scanning microscopy. Biotechnol Bioeng 2006;95(1):58-66.

[11] Lassen B, Malmsten M. Competitive protein adsorption studied with TIRF and ellipsometry. J Colloid Interface Sci 1996;179(2):470-7.

[12] Warkentin P, Walivaara B, Lundstrom I, Tengvall P. Differential surface binding of albumin, immunoglobulin $G$ and fibrinogen. Biomaterials 1994;15(10):786-95. 
[13] Wertz CF, Santore MM. Adsorption and relaxation kinetics of albumin and fibrinogen on hydrophobic surfaces: single-species and competitive behavior. Langmuir 1999;15(26):8884-94.

[14] Wertz CF, Santore MM. Effect of surface hydrophobicity on adsorption and relaxation kinetics of albumin and fibrinogen: single-species and competitive behavior. Langmuir 2001;17(10):3006-16.

[15] Dejardin P, ten Hove P, Yu XJ, Brash JL. Competitive adsorption of high molecular weight kininogen and fibrinogen from binary mixtures to glass surface. Langmuir 1995;11(10):4001-7.

[16] Green RJ, Davies MC, Roberts CJ, Tendler SJB. Competitive protein adsorption as observed by surface plasmon resonance. Biomaterials 1999;20(4):385-91.

[17] Vaidya SS, Ofoli RY. Adsorption and interaction of fibronectin and human serum albumin at the liquid-liquid interface. Langmuir 2005;21(13):5852-8.

[18] Arai T, Norde W. The behavior of some model proteins at solid-liquid interfaces. 2. Sequential and competitive adsorption. Coll Surf 1990;51:17-28.

[19] Alves CM, Reis RL, Hunt JA. Preliminary study on human protein adsorption and leukocyte adhesion to starch-based biomaterials. J Mater Sci Mater Med 2003;14(2):157-65.

[20] Higuchi A et al. Serum protein adsorption and platelet adhesion on pluronic (TM)-adsorbed polysulfone membranes. Biomaterials 2003:24(19):3235-45.

[21] Sousa SR, Lamghari M, Sampaio P, Moradas-Ferreira P, Barbosa MA. Osteoblast adhesion and morphology on TiO depends on the competitive preadsorption of albumin and fibronectin. J Biomed Mater Res A 2008;84A(2):281-90.

[22] Valiokas R, Svedhem S, Ostblom M, Svensson SCT, Liedberg B. Influence of specific intermolecular interactions on the self-assembly and phase behavior of oligo(ethylene glycol)-terminated alkanethiolates on gold. J Phys Chem B 2001;105(23):5459-69.

[23] Gispert MP, Serro AP, Colaço R, Saramago B. Bovine serum albumin adsorption onto 316L stainless steel and alumina: a comparative study using depletion, protein radiolabeling, quartz crystal microbalance and atomic force microscopy. Surf Interface Anal 2008;40(12):1529-37.

[24] Vörös J. The density and refractive index of adsorbing protein layers. Biophys J 2004;87(1):553-61

[25] Chiodi F, Sidén Å, Ösby E. Isoelectric focusing of monoclonal immunoglobulin $\mathrm{G}, \mathrm{A}$ and $\mathrm{M}$ followed by detection with the avidin-biotin system. Electrophoresis 1985;6(3):124-8.

[26] Procaccia $S$ et al. IgM, IgG and IgA rheumatoid factors and circulating immunecomplexes in patients with Aids and Aids-related complex with serological abnormalities. Clin Exp Immunol 1987;67(2):236-44.

[27] Giacomelli CE, Bremer MGEG, Norde W. ATR-FTIR study of IgG adsorbed on different silica surfaces. J Colloid Interface Sci 1999;220(1):13-23.

[28] Norde W, Favier JP. Structure of adsorbed and desorbed proteins. Coll Surf 1992;64(1):87-93.
[29] Norde W, Giacomelli CE. BSA structural changes during homomolecular exchange between the adsorbed and the dissolved states. J Biotech 2000;79(3):259-68.

[30] Arai T, Norde W. The behavior of some model proteins at solid-liquid interfaces. 1. Adsorption from single protein solutions. Coll Surf 1990;51: $1-15$.

[31] Sweryda-Krawiec B, Devaraj H, Jacob G, Hickman JJ. A new interpretation of serum albumin surface passivation. Langmuir 2004;20(6):2054-6.

[32] Zhou C, Friedt JM, Angelova A, Choi KH, Laureyn W, Frederix F, et al. Human immunoglobulin adsorption investigated by means of quartz crystal microbalance dissipation, atomic force microscopy, surface acoustic wave, and surface plasmon resonance techniques. Langmuir 2004;20(14):5870-8.

[33] Spector AA. Fatty acid binding to plasma albumin. J Lipid Res 1975;16(3):165-79.

[34] Giacomelli CE, Esplandiu MJ, Ortiz PI, Avena MJ, De Pauli CP. Ellipsometric study of bovine serum albumin adsorbed onto $\mathrm{Ti} / \mathrm{TiO}_{2}$ electrodes. J Colloid Interface Sci 1999;218(2):404-11.

[35] Wang J, Buck SM, Chen Z. The effect of surface coverage on conformation changes of bovine serum albumin molecules at the air-solution interface detected by sum frequency generation vibrational spectroscopy. Analyst 2003;128(6):773-8.

[36] Krishnan A, Liu Y-H, Cha P, Allara D, Vogler EA. Interfacial energetics of globular blood protein adsorption to a hydrophobic interface from aqueousbuffer solution. J R Soc Interface 2006;3(7):283-301.

[37] Wetterö J, Askendal A, Bengtsson T, Tengvall P. On the binding of complement to solid artificial surfaces in vitro. Biomaterials 2002;23(4):981-91.

[38] Silin V, Weetall H, Vanderah DJ. SPR studies of the nonspecific adsorption kinetics of human IgG and BSA on gold surfaces modified by self-assembled monolayers (SAMs). J Colloid Interface Sci 1997;185(1):94-103.

[39] Sheller NB, Petrash S, Foster MD, Tsukruk VV. Atomic force microscopy and Xray reflectivity studies of albumin adsorbed onto self-assembled monolayers of hexadecyltrichlorosilane. Langmuir 1998;14(16):4535-44.

[40] Lukkari J, Salomäki M, Ääritalo T, Loikas K, Laiho T, Kankare J. Preparation of multilayers containing conjugated thiophene-based polyelectrolytes. Layerby-layer assembly and viscoelastic properties. Langmuir 2002;18(22):8496-502.

[41] Messina GML, Satriano C, Marletta G. A multitechnique study of preferential protein adsorption on hydrophobic and hydrophilic plasma-modified polymer surfaces. Coll Surf B Biointerfaces 2009;70(1):76-83.

[42] Dutta AK, Nayak A, Belfort G. Viscoelastic properties of adsorbed and crosslinked polypeptide and protein layers at a solid-liquid interface. J Colloid Interface Sci 2008;324(1-2):55-60. 